\title{
Relationship between occupational stress and turnover intention among employees in a furniture manufacturing company in Selangor
}

\begin{abstract}
This study aims to investigate the relationship between occupational stress and turnover intention among employees in a furniture manufacturing company in Selangor state. A total of 95 respondents were randomly chosen by the researchers at a furniture manufacturing company in Selangor. The descriptive statistical analysis was used to analyse the demographic data of respondents, level of occupational stress, and level of turnover intention among employees in the selected furniture manufacturing company. Meanwhile, Pearson (r) correlation was used to examine the relationship between occupational stress and turnover intention among the employees. Result revealed that majority of the respondents experienced moderate level of occupational stress whereas more than half of the respondents were found to have moderate level of turnover intention. Result showed that occupational stress was significantly positively correlated with turnover intention. Further analysis also indicated that the dimensions of occupational stress such as organisational structure, social support, work overload, role conflict, and working environment were significantly correlated with turnover intention. In conclusion, there was a statistically significant positive relationship between occupational stress and turnover intention among the employees.
\end{abstract}

Keyword: Occupational stress; Turnover intention 